\title{
The role of inventories for the propagation of aggregate fluctuations: Lessons for Bulgaria (1999-2019)
}

May 24, 2021

\begin{abstract}
Purpose: Inventories are introduced as a productive input into a real-business-cycle (RBC) setup augmented with government.

Design/Methodology/Approach: The model is calibrated to Bulgarian data for the period 1999-2019. The quantitative importance of the presence of inventories is investigated.
\end{abstract}

Findings: The quantitative effect of inventories is found to be important: decreasing consumption volatility, and increasing employment variability. Those, results, however, are at the expense of decreasing wage volatility, and increasing investment volatility, and generally worsening the contemporaneous correlations of the main variables with output.

Originality/Value: Fluctuations in inventory levels matter for business cycle fluctuations in Bulgaria, which is a novel result. Still, there is need for more research on the incorporation of inventories into RBC models to fit better Bulgarian experience.

Keywords: business cycles, inventories, Bulgaria

JEL Classification Codes: E24, E32 


\section{Introduction and Motivation}

Even though inventory investment is just 0.4\% of GDP in Bulgaria, it varies more than twice than fixed investment in Bulgaria, which is $18.2 \%$ of GDP (NSI 2020). This stylized fact, which is also quite robust across countries and time, has led some researchers to suggest that fluctuations in inventory levels may be an important-, if not the main transmission mechanism of business cycle fluctuations. ${ }^{1}$ Still, there is still lack of proper quantitative investigation of the effect of inventory management in micro-founded, general equilibrium macroeconomic models. Earlier studies of inventories in RBC frameworks, e.g. Kydland and Prescott (1982) and Christiano (1988), do not study sufficiently in depth the effects of inventories for the business cycle.

This proposal is taken seriously, and this paper incorporates inventories as a productive input into an RBC framework. In the models, inventories are the finished and nearly-finished (or in process) goods, such as raw materials, fuels, etc. Relative to Christiano (1988), who estimates the model, here we calibrate the model due to the short series for Bulgaria. We also study the decentralized economy case, and allow for fiscal policy. ${ }^{2}$ The model is calibrated for Bulgaria in the period 1999-2019, as Bulgaria provides an interesting testing case for the theory, being the poorest EU member state, and and former transition economy. Given that the level of uncertainty is generally higher in Bulgaria relative to the other EU member states, inventory management is going to be more important. It comes as no surprise to use that the inventory investment, relative to output, is three times higher in Bulgaria than in the US. Thus, inventories are an important buffer in consumption and investment decisions.

The paper then proceeds to quantitatively evaluate the effect of the presence of inventories and their role for the stabilization of cyclical fluctuations in Bulgaria. The quantitative effect of inventories is found to be important: decreasing consumption volatility, and increas-

\footnotetext{
${ }^{1}$ The motivation comes from the literature on inventory management, e.g. the accelerator model in Blinder (1981), Blinder and Fischer (1981), and the references therein. We do not aim to make a detailed literature review, but instead emphasize what we don, which is novel for Bulgaria. For a recent survey of the literature on inventories, Ramey (1989) and Ramey and West (1999). Khan and Thomas (2007a,b) focus on the (S-s) rule of inventory management in a model with heterogeneous firms.

${ }^{2}$ Kydland and Prescott (1982) discuss only the social planner case as well.
} 
ing employment variability. Those, results, however, are at the expense of decreasing wage volatility, and increasing investment volatility, and generally worsening the contemporaneous correlations of the main variables with output. Overall, there is still work to be done on the incorporation of inventories into RBC models.

The rest of the paper is organized as follows: Section 2 describes the model framework and describes the decentralized competitive equilibrium system, Section 3 discusses the calibration procedure, and Section 4 presents the steady-state model solution. Sections 5 proceeds with the out-of-steady-state dynamics of model variables, and compared the simulated second moments of theoretical variables against their empirical counterparts. Section 6 concludes the paper.

\section{Model Description}

There is a representative households which derives utility out of consumption and leisure. The time available to households can be spent in productive use or as leisure. The government taxes consumption spending, levies a common proportional ("flat") tax on labor and capital income in order to finance wasteful purchases of government consumption goods, and government transfers. On the production side, there is a representative firm, which hires labor and capital to produce a homogeneous final good, which could be used for consumption, investment, or government purchases.

\subsection{Household's problem}

There is a representative household, which maximizes its expected utility function as in Hansen (1985):

$$
\max E_{0} \sum_{t=0}^{\infty} \beta^{t}\left\{\ln c_{t}-\gamma h_{t}\right\}
$$

where $E_{0}$ denotes household's expectations as of period $0, c_{t}$ denotes household's private consumption in period $t, h_{t}$ are hours worked in period $t, 0<\beta<1$ is the discount factor, $\gamma>0$ is the relative weight that the household attaches to leisure. 
The household starts with an initial stock of physical capital $k_{0}>0$, and has to decide how much to add to it in the form of new investment. The law of motion for physical capital is

$$
k_{t+1}=i_{t}^{k}+(1-\delta) k_{t}
$$

and $0<\delta<1$ is the depreciation rate. The real interest rate is $r_{t}^{k}$, hence the before-tax capital income of the household in period $t$ equals $r_{t}^{k} k_{t}$. In addition to investing in physical capital, the household can invest in inventory accumulation, which follows the following law of motion:

$$
i_{t}^{x}=x_{t+1}-x_{t} .
$$

The real interest rate on inventory capital is $r_{t}^{x}$. In addition to the two forms of capital income, the household can also generate labor income. Hours supplied to the representative firm are rewarded at the hourly wage rate of $w_{t}$, so pre-tax labor income equals $w_{t} h_{t}$. Lastly, the household owns the firm in the economy and has a legal claim on all the firm's profit, $\pi_{t}$.

Next, the household's problem can be now simplified to

$$
\max E_{0} \sum_{t=0}^{\infty} \beta^{t}\left\{\ln c_{t}-\gamma h_{t}\right\}
$$

s.t.

$$
\left(1+\tau^{c}\right) c_{t}+k_{t+1}-(1-\delta) k_{t}+x_{t+1}-x_{t}=\left(1-\tau^{y}\right)\left[r_{t}^{k} k_{t}+r_{t}^{x} x_{t}+w_{t} h_{t}+\pi_{t}\right]+g_{t}^{t}
$$

where where $\tau^{c}$ is the tax on consumption, $\tau^{y}$ is the proportional income tax rate on labor and capital income $\left(0<\tau^{c}, \tau^{y}<1\right)$, and $g_{t}^{t}$ denotes government transfers. The household takes the tax rates $\left\{\tau^{c}, \tau^{y}\right\}_{t=0}^{\infty}$, government spending categories, $\left\{g_{t}^{c}, g_{t}^{t}\right\}_{t=0}^{\infty}$, profit $\left\{\pi_{t}\right\}_{t=0}^{\infty}$, the realized technology process $\left\{A_{t}\right\}_{t=0}^{\infty}$, prices $\left\{w_{t}, r_{t}^{k}, r_{t}^{x}\right\}_{t=0}^{\infty}$, and chooses $\left\{c_{t}, h_{t}, k_{t+1}, x_{t+1}\right\}_{t=0}^{\infty}$ to maximize its utility subject to the budget constraint. ${ }^{3}$

\footnotetext{
${ }^{3}$ Note that by choosing $k_{t+1}$ and $x_{t+1}$ the household is implicitly setting capital and inventory investment $i_{t}^{k}$ and $i_{t}^{x}$ optimally.
} 
The first-order optimality conditions as as follows:

$$
\begin{array}{rll}
c_{t} & : \quad \frac{1}{c_{t}}=\lambda_{t}\left(1+\tau^{c}\right) \\
h_{t} & : \gamma=\lambda_{t}\left(1-\tau^{y}\right) w_{t} \\
k_{t+1} & : \lambda_{t}=\beta E_{t} \lambda_{t+1}\left[1+\left(1-\tau^{y}\right) r_{t+1}^{k}-\delta\right] \\
x_{t+1} & : \lambda_{t}=\beta E_{t} \lambda_{t+1}\left(1+r_{t+1}^{x}\right) \\
T V C & : \lim _{t \rightarrow \infty} \beta^{t} \lambda_{t} k_{t+1}=0 \\
T V C & : \lim _{t \rightarrow \infty} \beta^{t} \lambda_{t} x_{t+1}=0
\end{array}
$$

where $\lambda_{t}$ is the Lagrangean multiplier attached to household's budget constraint in period $t$. The interpretation of the first-order conditions above is as follows: the first one states that for each household, the marginal utility of consumption equals the so called "shadow price" of wealth, inclusive of the consumption tax rate. The second equation states that the benefit from working equals the cost at the margin. The third equation is the so-called "Euler condition," which describes how the household optimally chooses to accumulate physical capital over time. The last condition is called the "transversality condition" (TVC): it states that at the end of the optimization horizon, the shadow price of physical capital should be zero.

\subsection{Firm problem}

There is a stand-in firm in the economy, which produces a homogeneous product. The price of output is normalized to unity. The production technology follows that in Kydland and Prescott (1982) and Christiano (1988), and features inventories as a productive input. In particular, the firm uses physical capital, $k_{t}$, inventories, $x_{t}$, and labor hours, $h_{t}$, to maximize static profit

$$
\Pi_{t}=A_{t} h_{t}^{1-\alpha}\left[(1-\sigma) k_{t}^{-v}+\sigma x_{t}^{-v}\right]^{-\alpha / v}-r_{t}^{k} k_{t}-r_{t}^{x} x_{t}-w_{t} h_{t},
$$

where $A_{t}$ denotes the level of technology in period $t$. Since the firm rents the capital from households, the problem of the firm is a sequence of static profit maximizing problems. In equilibrium, there are no profits, and each input is priced according to its marginal product, 
i.e.:

$$
\begin{aligned}
& k_{t}: \quad \alpha \frac{y_{t}(1-\sigma) k_{t}^{-v-1}}{\left[(1-\sigma) k_{t}^{-v}+\sigma x_{t}^{-v}\right]}=r_{t}^{k}, \\
& x_{t}: \quad \alpha \frac{y_{t} \sigma x_{t}^{-v-1}}{\left[(1-\sigma) k_{t}^{-v}+\sigma x_{t}^{-v}\right]}=r_{t}^{x}, \\
& h_{t} \quad: \quad(1-\alpha) \frac{y_{t}}{h_{t}}=w_{t} .
\end{aligned}
$$

\subsection{Government}

The government is taxing labor and capital income, as well as consumption, in order to finance current expenditure, and government transfers. The government budget constraint is as follows:

$$
g_{t}^{c}+g_{t}^{t}=\tau^{c} c_{t}+\tau^{y}\left[w_{t} h_{t}+r_{t}^{k} k_{t}+r_{t}^{x} x_{t}\right]
$$

\subsection{Dynamic Competitive Equilibrium (DCE)}

For a given process followed by technology $\left\{A_{t}\right\}_{t=0}^{\infty}$, the tax rates $\left\{\tau^{c}, \tau^{y}\right\}_{t=0}^{\infty}$, and the initial capital stock and inventories $\left\{k_{0}, x_{0}\right\}$, the decentralized dynamic competitive equilibrium is a list of sequences $\left\{c_{t}, i_{t}, k_{t}, x_{t}, h_{t}\right\}_{t=0}^{\infty}$ for the household, a sequence of government purchases and transfers $\left\{g_{t}^{c}, g_{t}^{t}\right\}_{t=0}^{\infty}$, and input prices $\left\{w_{t}, r_{t}^{k}, r_{t}^{x}\right\}_{t=0}^{\infty}$ such that (i) the household maximizes its utility function subject to its budget constraint; (ii) the representative firm maximizes profit; (iii) government budget is balanced in each period; (iv) all markets clear.

\section{Data and Model Calibration}

To characterize business cycle fluctuations in Bulgaria, we will focus on the period following the introduction of the currency board (1999-2019). Quarterly data on output, consumption and investment was collected from National Statistical Institute (2020), while the real interest rate is taken from Bulgarian National Bank Statistical Database (2020). The calibration strategy described in this section follows a long-established tradition in modern macroeconomics, e.g. Kydland and Prescott (1982): first, as in Vasilev (2016), the discount factor, $\beta=0.982$, is set to match the steady-state capital-to-output ratio in Bulgaria, $k / y=13.964$, 
in the steady-state Euler equation. The labor share parameter, $1-\alpha=0.571$, is obtained as in Vasilev (2017), and equals the average value of labor income in aggregate output over the period. The share of inventories was set to its data average in Bulgarian Data, $\sigma=0.001$. The curvature parameter in the production function was set to $v=0.7$ to match the consumption-to-output ratio. Next, the average income tax rate was set to $\tau^{y}=0.1$, the average effective tax rate on income. Similarly, the average tax rate on consumption is set to its value over the period, $\tau^{c}=0.2$.

Next, the relative weight attached to the utility out of leisure in the household's utility function, $\gamma$, is calibrated to match that in steady-state consumers would work a third of their time endowmen. Next, the depreciation rate of physical capital in Bulgaria, $\delta=0.013$, was estimated as the average quarterly depreciation rate over the period. Finally, the process followed by the TFP process is estimated from the detrended Solow residuals by running an $\mathrm{AR}(1)$ regression and saving the residuals. Table 1 below summarizes the values of all model parameters used in the paper.

Table 1: Model Parameters

\begin{tabular}{llll}
\hline \hline Parameter & Value & Description & Method \\
\hline$\beta$ & 0.982 & Discount factor & Calibrated \\
$1-\alpha$ & 0.571 & Labor Share & Calibrated \\
$\sigma$ & 0.001 & Share of inventories in output & Data Avg. \\
$v$ & 0.700 & CES parameter, production function & Calibrated \\
$\gamma$ & 0.873 & Relative weight attached to leisure & Calibrated \\
$\delta$ & 0.013 & Depreciation rate on physical capital & Data Avg. \\
$\tau^{y}$ & 0.100 & Average tax rate on income & Data Avg. \\
$\tau^{c}$ & 0.200 & VAT/consumption tax rate & Data Avg. \\
$\rho_{a}$ & 0.701 & AR(1) persistence coefficient, TFP process & Estimated \\
$\sigma_{a}$ & 0.044 & st. error, TFP process & Estimated \\
\hline
\end{tabular}




\section{Steady-State}

Once the steady-state equilibrium system has been solved, the theoretical ratios can be compared to their averages in Bulgarian data. The results are reported in Table 2 below. The model matches consumption-to-output and government purchases ratios by construction; The investment ratios are also closely approximated. The shares of income are also identical to those in data; the after-tax return, where $\bar{r}=\left(1-\tau^{y}\right) r-\delta$ is also relatively well-captured by the model.

Table 2: Data Averages and Long-run Solution

\begin{tabular}{llll}
\hline \hline Variable & Description & Data & Model \\
\hline$y$ & Steady-state output & N/A & 1.000 \\
$c / y$ & Consumption-to-output ratio & 0.648 & 0.674 \\
$i / y$ & Fixed Investment-to-output ratio & 0.182 & 0.156 \\
$x / y$ & Inventory investment-to-output ratio & 0.019 & 0.019 \\
$k / y$ & Capital-to-output ratio & 13.96 & 13.96 \\
$g^{c} / y$ & Government consumption-to-output ratio & 0.151 & 0.151 \\
$w h / y$ & Labor income-to-output ratio & 0.571 & 0.571 \\
$r^{k} k / y$ & Capital income-to-output ratio & 0.428 & 0.428 \\
$r^{x} x / y$ & Inventory income-to-output ratio & 0.001 & 0.001 \\
$h$ & Share of time spent working & 0.333 & 0.333 \\
$\bar{r}$ & After-tax net return on capital & 0.014 & 0.016 \\
\hline
\end{tabular}

\section{Out of steady-state model dynamics}

The model does not have an analytical solution for the equilibrium behavior of variables outside their steady-state values, so we need to solve the model numerically by log-linearizing the non-linear system of equations around the steady-state. Then, we study the dynamic behavior of model variables to an isolated shock to the total factor productivity process, and then compare how the second moments of the model compare to the empirical ones. 


\subsection{Impulse Response Analysis}

This subsection documents the impulse responses of model variables to a $1 \%$ surprise innovation to total factor productivity. As seen in Fig. 1, after a one-time unexpected positive shock to total factor productivity, output increases upon impact. In turn, all uses of output - consumption, investment in capital and inventories, and government consumption, also increase contemporaneously. Next, the increase in productivity increases the after-tax return on the factors of production, labor, capital, and inventories. The representative household responds to these incentives and start accumulating capital, inventory, and works more. The increase in labor, inventories and capital input feed back through the production function and further increase output.
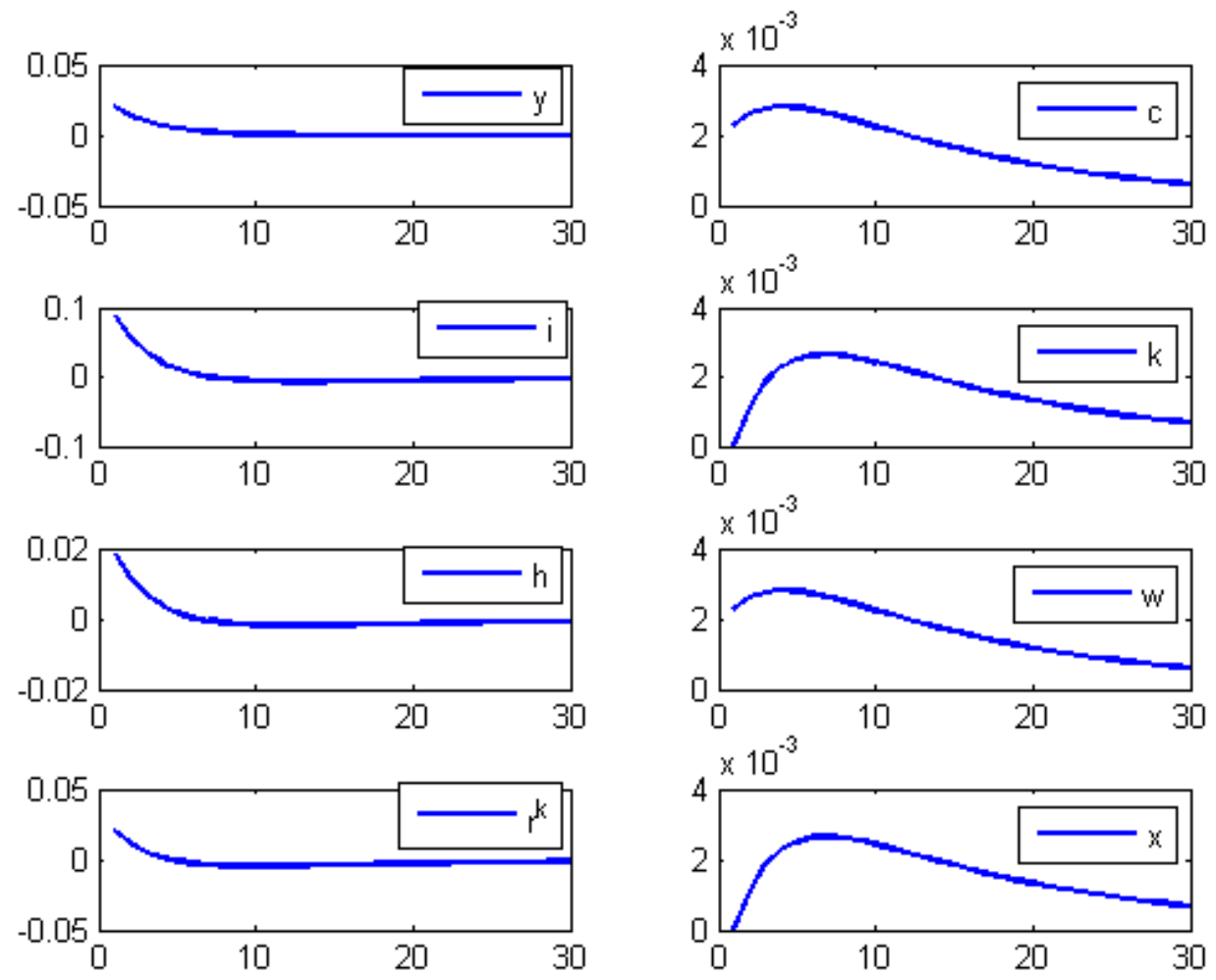

Figure 1: Impulse Responses to a 1\% surprise innovation in technology

Over time, the law of diminishing marginal product enters the picture, which lowers the households' incentives to save - physical capital stock and inventory levels eventually returns 
to its steady-state, and exhibits a hump-shaped dynamics over its transition path. The rest of the model variables return to their old steady-states in a monotone pattern.

\subsection{Simulation and moment-matching}

We now simulate the model, with both empirical and model simulated data is HP-filtered. Table 3 on the next page summarizes the second moments of empirical data versus the model-simulated ones. The "Model" is the case with inventories, while the "Benchmark RBC" is a setup without inventories.

Both models match quite well the absolute volatility of output and investment. In addition, the predicted consumption volatility in the model with inventories is closely matched, but investment volatility is too high. Still, the model is consistent with the fact that consumption is smoother than output, while investment is more variable than output. Unfortunately, the volatility of inventories is way lower than the variability observed in data.

Next, the variability of employment in the model is higher than that in data, but much better than the case without inventories. On the other hand, the presence of inventories makes variability of wages in the model drop much lower than that in data. In terms of contemporaneous correlations, the model systematically over-predicts the pro-cyclicality investment, and government consumption, while it underpredicts the contemporanenous correlation of consumption with output. Inventories are predicted to be strongly counter-cyclical, while in data the effect is much weaker.The contemporaneous correlation of employment with output is also predicted to be too high. With respect to wages, the model generates moderate cyclicality, while in data the average wage is acyclical; still, the presence of inventories decreases the correlation almost by a third relative to the case without inventories.

In the next subsection, as in Vasilev (2016), we investigate the dynamic correlation between labor market variables at different leads and lags; the autocorrelation functions (ACFs) of empirical data are compared and contrasted to the simulated ones from the model. 
Table 3: Business Cycle Moments

\begin{tabular}{llll}
\hline \hline & Data & Model & Benchmark RBC \\
\hline$\sigma_{y}$ & 0.05 & 0.05 & 0.05 \\
$\sigma_{c} / \sigma_{y}$ & 0.55 & 0.54 & 0.82 \\
$\sigma_{i} / \sigma_{y}$ & 1.77 & 3.75 & 2.35 \\
$\sigma_{x} / \sigma_{y}$ & 3.96 & 0.53 & - \\
$\sigma_{g} / \sigma_{y}$ & 1.21 & 1.00 & 1.00 \\
$\sigma_{h} / \sigma_{y}$ & 0.63 & 0.78 & 0.28 \\
$\sigma_{w} / \sigma_{y}$ & 0.83 & 0.54 & 0.86 \\
$\sigma_{y / h} / \sigma_{y}$ & 0.86 & 0.54 & 0.86 \\
\hline $\operatorname{corr}(c, y)$ & 0.85 & 0.60 & 0.90 \\
$\operatorname{corr}(i, y)$ & 0.61 & 0.90 & 0.83 \\
$\operatorname{corr}(x, y)$ & -0.06 & -0.61 & - \\
$\operatorname{corr}(g, y)$ & 0.31 & 1.00 & 1.00 \\
$\operatorname{corr}(h, y)$ & 0.49 & 0.82 & 0.59 \\
$\operatorname{corr}(w, y)$ & -0.01 & 0.60 & 0.96 \\
\hline
\end{tabular}

\subsection{Auto- and cross-correlation}

This subsection discusses the coefficients of the auto-(ACFs) and cross-correlation functions (CCFs) of the major model variables. Table 4 summarizes the averaged simulated AFCs and CCFs.

As seen from Table 4 above, the empirical ACFs for output and investment are slightly outside the confidence band predicted by the model, while the ACFs for total factor productivity and household consumption are well-approximated by the model. The persistence of labor market variables are also relatively well-described by the model dynamics. Next, as seen from Table 5 below, over the business cycle, labor productivity is a leading variable. The model, however, cannot account for this fact. As in the standard RBC model a technology shock produces only a contemporaneous effect between employment and labor productivity. 
Table 4: Autocorrelations for Bulgarian data and the model economy

\begin{tabular}{|c|c|c|c|c|c|}
\hline & & $\mathrm{k}$ & & & \\
\hline Method & Statistic & 0 & 1 & 2 & 3 \\
\hline Data & $\operatorname{corr}\left(n_{t}, n_{t-k}\right)$ & 1.000 & 0.484 & 0.009 & 0.352 \\
\hline Model & $\operatorname{corr}\left(n_{t}, n_{t-k}\right)$ & 1.000 & 0.953 & 0.896 & 0.828 \\
\hline & (s.e.) & $(0.000)$ & $(0.029)$ & $(0.056)$ & $(0.082)$ \\
\hline Data & $\operatorname{corr}\left(y_{t}, y_{t-k}\right)$ & 1.000 & 0.810 & 0.663 & 0.479 \\
\hline Model & $\operatorname{corr}\left(y_{t}, y_{t-k}\right)$ & 1.000 & 0.954 & 0.899 & 0.835 \\
\hline & (s.e.) & $(0.000)$ & $(0.028)$ & $(0.054)$ & $(0.079)$ \\
\hline Data & $\operatorname{corr}\left(a_{t}, a_{t-k}\right)$ & 1.000 & 0.702 & 0.449 & 0.277 \\
\hline Model & $\operatorname{corr}\left(a_{t}, a_{t-k}\right)$ & 1.000 & 0.955 & 0.900 & 0.837 \\
\hline & (s.e.) & $(0.000)$ & $(0.028)$ & $(0.054)$ & $(0.079)$ \\
\hline Data & $\operatorname{corr}\left(c_{t}, c_{t-k}\right)$ & 1.000 & 0.971 & 0.952 & 0.913 \\
\hline Model & $\operatorname{corr}\left(c_{t}, c_{t-k}\right)$ & 1.000 & 0.958 & 0.909 & 0.854 \\
\hline & (s.e.) & $(0.000)$ & $(0.025)$ & $(0.049)$ & $(0.072)$ \\
\hline Data & $\operatorname{corr}\left(i_{t}, i_{t-k}\right)$ & 1.000 & 0.810 & 0.722 & 0.594 \\
\hline Model & $\operatorname{corr}\left(i_{t}, i_{t-k}\right)$ & 1.000 & 0.953 & 0.896 & 0.829 \\
\hline & (s.e.) & $(0.000)$ & $(0.029)$ & $(0.056)$ & $(0.081)$ \\
\hline Data & $\operatorname{corr}\left(w_{t}, w_{t-k}\right)$ & 1.000 & 0.760 & 0.783 & 0.554 \\
\hline Model & $\operatorname{corr}\left(w_{t}, w_{t-k}\right)$ & 1.000 & 0.958 & 0.909 & 0.854 \\
\hline & (s.e.) & $(0.000)$ & $(0.025)$ & $(0.049)$ & $(0.072)$ \\
\hline
\end{tabular}

\section{Conclusions}

Inventories are introduced as a productive input into a real-business-cycle setup with government. The model is calibrated to Bulgarian data for the period 1999-2019. The quantitative importance of the presence of inventories is investigated. The quantitative effect of inventories is found to be important: decreasing consumption volatility, and increasing employment variability. Those, results, however, are at the expense of decreasing wage volatility, and increasing investment volatility, and generally worsening the contemporaneous correlations of the main variables with output. In addition, even though the model correctly predicts 
Table 5: Dynamic correlations for Bulgarian data and the model economy

\begin{tabular}{|c|c|c|c|c|c|c|c|c|}
\hline & & $\mathrm{k}$ & & & & & & \\
\hline Method & Statistic & -3 & -2 & -1 & 0 & 1 & 2 & 3 \\
\hline Data & $\operatorname{corr}\left(h_{t},(y / h)_{t-k}\right)$ & -0.342 & -0.363 & -0.187 & -0.144 & 0.475 & 0.470 & 0.346 \\
\hline \multirow[t]{2}{*}{ Model } & $\operatorname{corr}\left(h_{t},(y / h)_{t-k}\right)$ & 0.085 & 0.081 & 0.073 & 0.135 & -0.029 & -0.054 & -0.069 \\
\hline & (s.e.) & $(0.337)$ & $(0.295)$ & $(0.245)$ & $(0.350)$ & $(0.219)$ & $(0.258)$ & $(0.295)$ \\
\hline Data & $\operatorname{corr}\left(h_{t}, w_{t-k}\right)$ & 0.355 & 0.452 & 0.447 & 0.328 & -0.040 & -0.390 & -0.57 \\
\hline \multirow[t]{2}{*}{ Model } & $\operatorname{corr}\left(h_{t}, w_{t-k}\right)$ & 0.085 & 0.081 & 0.073 & 0.135 & -0.029 & -0.054 & -0.069 \\
\hline & (s.e.) & $(0.337)$ & $(0.295)$ & $(0.245)$ & $(0.350)$ & $(0.219)$ & $(0.258)$ & $(0.295)$ \\
\hline
\end{tabular}

inventories to be counter-cyclical, the effect is much milder in data; further, inventories in the model vary much less than the observed variability in data. Overall, there is still a lot of work that needs to be done on the incorporation of inventories into RBC models. This is left for future research.

\section{References}

Blinder, A.S. (1981) "Retain inventory behavior and business fluctuations," Brookings Papers on Economic Activity 2, 443-505.

Blinder, A.S. and S. Fischer (1981) "Inventories, rational expectations, and the business cycle," Journal of Monetary Economics 8, 277-304.

Bulgarian National Bank. 2020. Bulgarian National Bank Statistics. Available on-line at www.bnb.bg. Accessed on Nov.1, 2020.

Christiano, L. (1988) "Why does inventory investment fluctuate so much?", Journal of Monetary Economics 21, 247-280.

Hansen, G. (1985) "Indivisible labor and the business cycle," Journal of Monetary Economics 16, 309-327. 
Khan, A., and J. K. Thomas (2007a). "Explaining Inventories: A Business Cycle Assessment Of The Stockout Avoidance and (S,s) Motives," Macroeconomic Dy- namics, 11(05), 638-664.

Khan, A., and J. K. Thomas (2007b): "Inventories and the Business Cycle: An Equilibrium Analysis of (S, s) Policies," American Economic Review, 97(4), 11651188.

Kydland, Finn and E.C. Prescott (1982) "Time to build and aggregate fluctuations," Econometrica 50, 1345-1370.

National Statistical Institute. 2020. Aggregate Statistical Indicators. Available on-line at www.nsi.bg. Accessed on Nov. 1, 2020.

Ramey, V (1989), "Inventories as factors of production and economic fluctuations," American Economic Review, Vol. 79, pages 33854.

Ramey, Valerie A., and K.D. West. (1999) "Inventories," in M. Woodford and J. Taylor (eds.), Handbook of Macroeconomics IB, pp. 863-927.

Vasilev, A. (2017). "Progressive taxation and (in)stability in an exogenous growth model with an informal sector," Journal of Economics and Econometrics 60(2): 1-13.

Vasilev, A. (2016). "Progressive taxation and (in)stability in an endogenous growth model with human capital accumulation," Journal of Economics and Econometrics 59(2): 1-15. 